\title{
Entre o ideal e o possível: caminhos de formação docente por meio das rodas de conversa on-line
}

\author{
Between ideal and possible: paths of teacher training through on-line \\ conversation wheels
}

Alexandre José de Carvalho Silva Mestrado em Educação Universidade Federal de Lavras - UFLA Lavras, MG - Brasil alexandresilva@ufla.br

Sayonara Ribeiro Marcelino Cruz Mestrado em Educação Universidade Federal de Lavras - UFLA Lavras, MG - Brasil sayonaracruz@ufla.br

iD Warlley Ferreira Sahb Doutor em Educação Universidade Federal de Lavras - UFLA Lavras, MG - Brasil ferreira@ufla.br

Resumo: $\mathrm{O}$ artigo objetiva compartilhar as ações de formação docente, criadas na UFLA, como resposta às demandas emergidas no atual contexto de pandemia. Fundamenta-se na pesquisa qualitativa, caracterizando como descritiva, tomando como base o modelo TPACK (MISHRA e KOELLER, 2006) como ferramenta teórica na edificação das ações e nas análises do percurso e dos dados produzidos. Almejamos colaborar com o registro histórico dos enormes desafios educacionais enfrentados de forma inédita por nossa geração neste contexto e contribuir para a reflexão da importância das formações continuadas de conhecimentos pedagógicos e tecnológicos para uma efetiva ação de retomada da educação formal por meios de recursos tecnológicos. Face aos resultados obtidos, pode-se deduzir que propostas de formação continuada usando as rodas de conversa on-line contribuem para adquirir competências para identificar abordagens metodológicas e pedagógicas que se encaixam em diferentes situações de aprendizagem utilizando as tecnologias. Nesse sentido, favorecem a inclusão digital no sentido de despertar as competências docentes para a utilização das TDIC com autonomia e destreza, em consonância com as demandas da contemporaneidade.

Palavras-chave: Ensino híbrido. Ensino remoto emergencial. Formação de professores.

Abstract: The article aims to share the teacher training actions, created at UFLA, in response to the demands emerging in the current pandemic context. It is based on qualitative research, characterizing it as descriptive, based on the TPACK model (MISHRA and KOELLER, 2006) as a theoretical tool in the construction of actions and in the analysis of the route and data produced. We aim to collaborate with the historical record of the enormous educational challenges faced in an unprecedented way by our generation in this context and to contribute to the reflection of the importance of the continued training of pedagogical and technological knowledge for an effective action to resume formal education through technological resources. In view of the results obtained, it can be deduced that proposals for continuing education using virtual spaces with synchronous and asynchronous activities make it possible to acquire skills to identify methodological and pedagogical approaches that fit into different learning situations using technologies. In this way, they favor digital inclusion in the sense of awakening the teaching skills for the use of TDIC with autonomy and dexterity, in line with the demands of contemporary times.

Keywords: Blended Learning. Emergency remote education. Teacher training. 


\section{Introdução}

Trabalhos que visam discutir sobre a educação mediada por tecnologias tendem a iniciarse pautando as grandes e rápidas mudanças que a intensa presença das tecnologias digitais de informação e comunicação (TDIC) têm causado em todos os âmbitos da sociedade, onde se incluem os processos educacionais. E nisso já se vão décadas, onde a importância da adesão da escola às transformações digitais é reconhecida e enfatizada sem, contudo, apresentar efetivas mudanças nas práticas e processos de ensinar e aprender.

Em se tratando da Educação a Distância (EaD), muito se fala de sua expansão nos últimos tempos, entretanto, é apresentada tanto no âmbito legal quanto nos discursos ideológicos como uma modalidade educacional onde são utilizados meios virtuais para se permitir a relação de profissionais da educação e estudantes, quando ela estiver dificultada por questões referentes ao distanciamento geográfico e/ou temporal entre os sujeitos envolvidos nos processos educacionais.

Jamais imaginaríamos que num curto espaço de tempo essas discussões se convergiriam, num movimento que propõe (ou ao menos deveria) transpor um fosso ideológico criado entre ensino presencial e o ensino a distância, e que ganharia o nome de Estudos Remotos Emergenciais (ERE), colocando todos num mesmo barco ou pelo menos sob a mesma tempestade, uma vez que o Ministério da Educação (MEC) publicou a Portaria no 343 de 17 de março de 2020, que permitiu a substituição das aulas presenciais por aulas em meios digitais enquanto perdurar a situação de pandemia do Coronavírus - COVID-19.

Neste cenário, nós que atuamos diretamente com a formação continuada dos professores da Universidade Federal de Lavras - UFLA, nos deparamos com a questão do despreparo de parte do corpo docente para atuar nos ambientes virtuais de aprendizagem e utilizar técnica e pedagogicamente os recursos e aparatos tecnológicos disponíveis nestas plataformas on-line.

Diante disso, se impõe a seguinte questão: como formar docentes, desenvolvendo competências tecnológicas e pedagógicas, em curto prazo, para que estejam aptos para preparar materiais, gravar aulas, escolher ferramentas e buscar recursos que ajudem a enfrentar os desafios da educação on-line? Como trabalhar com grupos heterogêneos em relação ao nível de apropriação e competência tecnológica?

Destacamos que o processo de formação para apropriação e uso de saberes e práticas vinculados às tecnologias digitais têm pautado as ações institucionais de formação continuada desde 2009, quando foi lançado o Projeto Aprender, que tinha como principal objetivo a implementação e disponibilização de um Ambiente Virtual de Aprendizagem (AVA) para os cursos de graduação da UFLA. 
E, somando ações de qualificação e formação continuada dos docentes à implementação desse projeto, devemos também dar destaque para o fortalecimento do Projeto PRODOCENTE que se caracteriza como um conjunto de ações que tem a finalidade de promover, de forma contínua, a ações de formação para os docentes da universidade. Em 2018 a Diretoria de Avaliação e Desenvolvimento do Ensino (DADE) promove a reformulação do Projeto PRODOCENTE, ampliando suas ações e seus objetivos, passando estes a serem os seguintes: a) fomentar as ações de formação continuada de professores da UFLA com vistas à ampliação das discussões acerca da docência no Ensino Superior, seus desafios e possibilidades; e b) ampliar as ações de qualificação da docência e dos processos de ensino e de aprendizagem no âmbito da sala de aula (relação professor-aluno; metodologias; processos avaliativos e de acompanhamento da aprendizagem; planejamento e organização da aula; práticas pedagógicas e inovações etc.).

Este artigo tem como objetivo compartilhar as ações de formação docente, criadas na UFLA, como resposta às demandas emergidas no atual contexto de pandemia causada pelo vírus COVID-19 que levou a paralisação do calendário acadêmico em meados do mês de março de 2020. Os autores deste relato de experiência, com o apoio da Pró-reitoria de Graduação (PROGRAD), idealizaram e desenvolveram, no período compreendido entre abril a agosto de 2020, trinta e seis (36) ações de formação com docentes e estudantes visando a retomada dos estudos, de forma remota, do calendário acadêmico a partir de $1^{\circ}$ de junho do corrente ano.

Nestas formações tivemos a participação de mais de 590 pessoas, destacando-se entre estes o equivalente a dois terços $(2 / 3)$ do número total docentes da instituição, sendo esse o processo de formação docente continuada de maior capilaridade e alcance da história centenária da UFLA.

Foi desenvolvida uma formação direcionada aos discentes, pois para estes também o processo de estudos remotos emergenciais seria novidade. A formação foi construída de forma colaborativa por uma equipe de diferentes áreas, com sugestões de melhores formas de estudo a distância, normas dos estudos remotos, recursos disponíveis no ambiente virtual e psicologia positiva diante deste novo contexto. O curso foi elaborado em formato de MOOC (Massive Open On-line Course) e foram certificados cerca de 7200 discentes da instituição.

$\mathrm{O}$ artigo fundamenta-se na pesquisa qualitativa, caracterizando como descritiva, tomando como base o modelo TPACK (MISHRA e KOELLER, 2006) como ferramenta teórica na edificação das ações e nas análises do percurso e dos dados produzidos. Para tanto, apresentaremos as bases teóricas que fundamentam as ações, a forma como as ações foram organizadas e refletiremos sobre os resultados iniciais deste percurso formativo. 
Compartilhando essa experiência, acreditamos colaborar com o registro histórico dos enormes desafios educacionais, enfrentados de forma inédita por nossa geração neste contexto de pandemia, e também contribuir para a reflexão da importância das formações continuadas de conhecimentos pedagógicos e tecnológicos para uma efetiva ação de retomada da educação formal por meios de recursos tecnológicos.

Caminhos de formação docente: diálogos possíveis entre o pedagógico e o tecnológico

Inicialmente, consideramos imprescindível algumas reflexões acerca das bases sobre as quais as nossas ações de formação docente se assentam, ou seja, informar o que entendemos por formação docente e apresentar, ainda que sucintamente, o Programa de Formação Continuada desenvolvido desde de 2016 pela nossa IES.

Criada no ano de 2016, a DADE, órgão vinculado à PROGRAD/UFLA, tem se constituído como a instância responsável pelo processo de planejamento, articulação e gestão das diversas ações de formação docente na UFLA. Tais processos formativos encontram-se ancorados em quatro dimensões: discussões conceituais, compartilhamento de experiências, capacitação técnica e aprimoramento de práticas de ensino. Fundados nos referenciais de docência universitária (CUNHA,2008; ALMEIDA, 2012; ALMEIDA E TORRES, 2013), campo de conhecimento que tem contribuído com formulação de políticas institucionais de formação docente visando assegurar a qualidade do trabalho da universidade na contemporaneidade, expressa o compromisso com o desenvolvimento profissional docente.

Esses processos continuados de formação tomam a prática pedagógica como base epistemológica para a construção de uma proposta coletiva e dialógica tendo os professores como protagonistas desse processo.

Nesse escopo - de formação continuada de docentes - consideramos que grande avanço se deu por ação iniciada pela Pró-reitoria de Graduação com a criação da Semana de Planejamento e Formação Docente (SPFD), que se caracteriza como sendo uma ação integrante do Programa PRODOCENTE que ocorre no início de cada semestre letivo, sendo inclusive suas datas de realizações anualmente definidas no calendário acadêmico da graduação aprovado pelo Conselho de Ensino, Pesquisa e Extensão (CEPE) da UFLA. Tais propostas têm se materializado por de meio de palestras, oficinas e fóruns de debates, compondo as ações do programa de formação continuada dos docentes, conforme pode ser visto no quadro abaixo: 


\section{Dialogia}

SILVA, Alexandre José de Carvalho; CRUZ, Sayonara Ribeiro Marcelino; SAHB, Warlley Ferreira. Entre o ideal e o possível: caminhos de formação docente por meio das rodas de conversa on-line

\begin{tabular}{|l|c|}
\begin{tabular}{|l|} 
Quadro 1 - Relatório de ações \\
Relatório de ações de formação docente - 2017 a 2019 \\
PROGRAMA PRODOCENTE
\end{tabular} \\
\hline \begin{tabular}{|l|c|} 
Semana de Planejamento e Formação Docente (SPFD) \\
Oficinas
\end{tabular} & 89 \\
\hline Palestras & 18 \\
\hline Minicursos & 3 \\
\hline Certificações & 8.708 \\
\hline
\end{tabular}

Fonte: Relatório de gestão DADE/UFLA.

Mas o que os professores precisam saber para ensinar com as tecnologias?

A natureza complexa dos processos de ensino e aprendizagem revela também a complexidade dos saberes docente. A teoria de Shulman $(1986,1987)$, conhecimento pedagógico de conteúdo (PCK), tem sido uma das mais bem aceitas para explicar os saberes necessários à docência.

Segundo esse referencial, a união entre esses componentes (conhecimento de conteúdo específico e conhecimento pedagógico) é eficaz no sentido de como organizar, adaptar e representar conceitos, questões e problemas de maneira que se tornem compreensíveis para os estudantes. A esse know-how dos professores, Mishra e Kohler (2006) acrescentaram um terceiro componente: o conhecimento tecnológico, cunhando a estrutura denominada "Conhecimento tecnológico de conteúdo pedagógico" (TPCK), que mais tarde foi renomeado TPACK (Figura 1 ). 


\section{Dialogia}

SILVA, Alexandre José de Carvalho; CRUZ, Sayonara Ribeiro Marcelino; SAHB, Warlley Ferreira. Entre o ideal e o possível: caminhos de formação docente por meio das rodas de conversa on-line

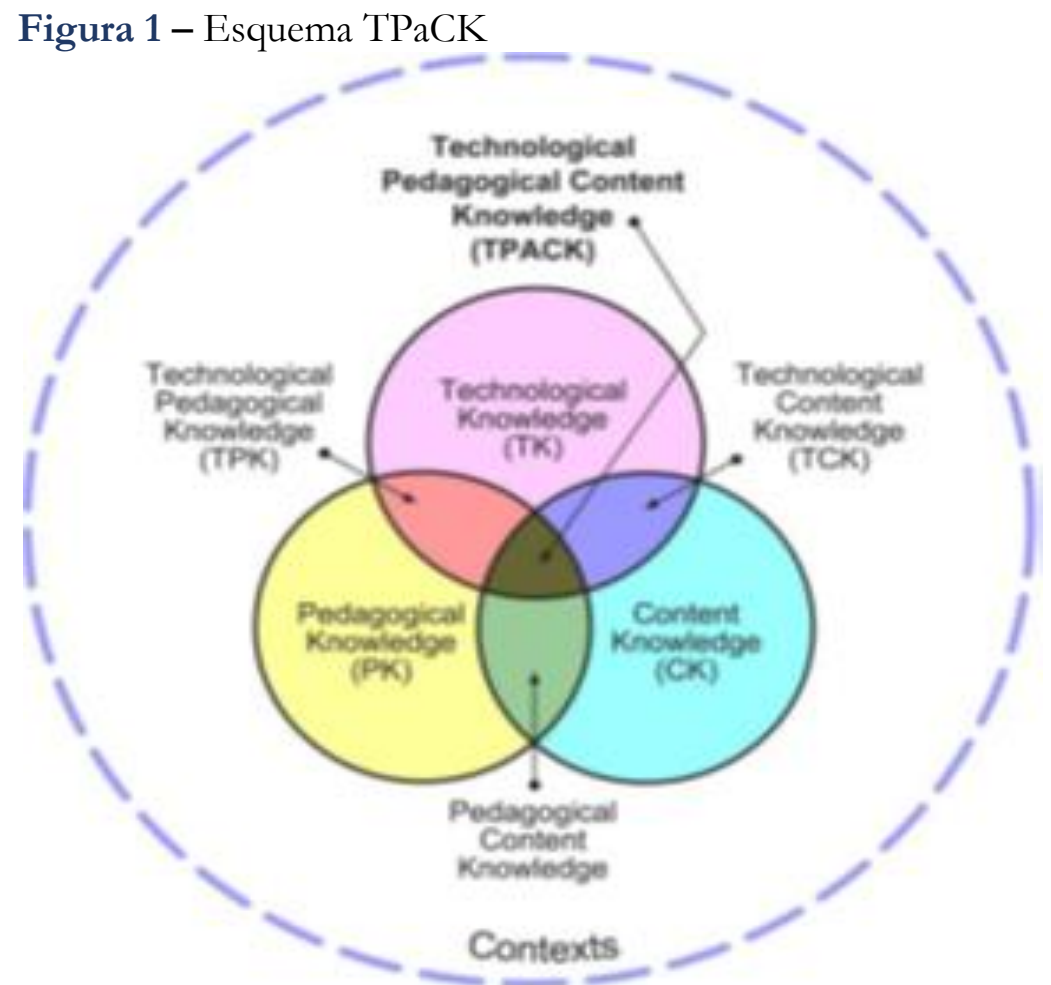

Fonte: http://www.tpack.org. Acesso em: 03/07/2020.

Segundo esse quadro teórico uma boa estratégia para a integração das Tecnologias Digitais de Informação e Comunicação (TDIC) ao currículo escolar é a mistura balanceada de conhecimentos nos níveis: científico (ou dos conteúdos), pedagógico e tecnológico. A proposta, neste caso, combina as relações entre o conhecimento do tema que será trabalhado em aula; as práticas, processos, estratégias, e métodos para ensinar e o uso de computadores, Internet, vídeo digital, entre outras tecnologias (CRUZ e MARTINS, 2016).

Cox (2009) nos oferece uma definição da TPCAK, que vai ao encontro do que buscamos em nossas ações de formação por meio das rodas de conversa:

\footnotetext{
Conhecimento pedagógico de conteúdo tecnológico consiste na articulação entre conteúdo, pedagogia, e como essa negociação afeta a aprendizagem do aluno de contexto de sala de aula. As características essenciais são (a) o uso de tecnologia (b) em uma área de conteúdo específica (c) como parte de uma estratégia pedagógica (d) dentro de um determinado contexto educacional (e) para desenvolver o conhecimento dos alunos sobre um tópico específico ou atender a um objetivo educacional ou necessidade do aluno. (p. 40)
}

O processo que antecedeu as rodas de conversas on-line iniciou-se com uma pesquisa sobre temáticas mais relevantes, ferramentas e recursos ao contexto emergencial, definição de uma metodologia coerente com nossas concepções teóricas e que contemplassem aspectos técnicos e 
pedagógicos. Para tanto, nos apoiamos neste aporte conceitual que já vinha sendo estudado há algum tempo.

Entre o ideal e o possível: operacionalizando as rodas de conversa online

Quando a pandemia chegou, nos pegou em meio a organização de um Congresso interinstitucional, previsto para abril de 2020, que discutiria a inovação e metodologias no ensino superior. De repente, como consequência do contexto emergencial de quarentena provocada pelo Covid-19, o calendário acadêmico da instituição foi paralisado e fomos para casa dar continuidade às nossas atividades por meio de trabalho remoto. Uma sequência de portarias, decretos, resoluções foram chegando com diretrizes e orientações para utilização de webconferências, ferramentas de trabalho em equipe, disponibilização de materiais de estudo.

Para que a universidade não ficasse totalmente parada, inicialmente foi sugerido aos docentes oferecer atividades de recuperação, fomentar estudos autônomos aos estudantes e trabalhos com temas transversais. Além de cursos de extensão em áreas que poderiam ser relevantes neste período de distanciamento social.

Foi pensando neste contexto de desafios para a docência no ensino superior que a DADE, responsável pelo assessoramento pedagógico e pela formação continuada dos professores da UFLA, juntamente com a Coordenadoria Geral de Educação a Distância (CEAD/DADE), coordenadoria responsável pelas ações de educação a distância e pela manutenção e assessoramento na utilização da plataforma Campus Virtual, elaboraram uma proposta de formação visando capacitar os docentes a utilizar as TDIC para dar continuidade em suas ações, manter contato com seus pares e utilizarem das metodologias de Educação a Distância para as atividades de trabalho/estudo remoto.

$\mathrm{Na}$ universidade os processos de formação continuada sempre foram baseados em encontros presenciais, cursos, palestras, mesas-redondas e oficinas semipresenciais, mas neste novo contexto e buscando uma metodologia alinhada com nossas concepções teóricas, e privilegiando a perspectiva dialógica possibilitando a formação de uma rede de aprendizagem colaborativa, foi proposta uma ação intitulada "Rodas de Conversa On-line", que tiveram como principais objetivos: ajudar professores a se familiarizarem com as ferramentas disponíveis no Campus Virtual (Moodle), fomentar os estudos autônomos, apresentar formas de se obter e utilizar os Recursos Educacionais Abertos (REAs), apresentar e analisar as opções de recursos que permitem a realização de transmissões com áudio e vídeo de forma gratuita e eficaz, e outros meios de interação entre professores e estudantes. 
Para além de um mero título, como metodologia de trabalho, as Rodas de Conversa On-line foram utilizadas como dispositivos de construção dialógica, ancoradas nos estudos de Paulo Freire, possibilitando a construção de conhecimentos coletivos e contextualizados. Desse modo, as rodas propuseram uma reflexão crítica, assumindo os riscos, desafios e mudanças como fundamentos de uma educação problematizadora/libertadora.

E, posteriormente, com a confirmação da retomada dos estudos de forma remota, foi proposto estender a formação também para os discentes, que tiveram como principais objetivos: esclarecer como se daria o processo de estudos remotos emergenciais, quais os prazos, regras e melhor forma de estudar neste novo contexto, além de dicas de como encarar de forma produtiva e proativa este grande desafio de estudo, diferente do habitual.

Fizemos a divulgação inicial do processo de formação através da lista de e-mails dos docentes e também produzimos uma arte com uma logomarca para as rodas de conversa. Fizemos a divulgação da primeira Roda de Conversa logo em meados de março e prevíamos uma participação de cerca de 30 docentes mas fomos positivamente surpreendidos com a participação de cerca de 160 docentes. Isto nos mostrou que o momento e o formato eram propícios, que já havia um engajamento dos docentes e uma preocupação sobre como aproveitar bem o tempo de reclusão social e trabalho remoto. Sendo importante ressaltar que naquele momento não havia definição sobre a volta aos estudos de forma remota.

De meados de março a agosto foram realizadas trinta e seis (36) rodas de conversa com uma participação média de 165 pessoas, utilizando o Google Meet e o StreamYard, sendo planejadas para a duração média de 80 minutos. Quanto aos assuntos tratados, podem ser divididos em quatro tipos: Rodas de conversa com característica mais técnica, com a demonstração e discussão de como utilizar determinados recursos, a indicação de repositórios e como localizar materiais educacionais disponíveis na internet; rodas de caráter pedagógico, com discussões mais conceituais sobre determinadas abordagens ou metodologias; um terceiro tipo com compartilhamento de experiências e práticas pedagógicas pelos próprios docentes; e o quarto tipo foram rodas com orientações sobre como iria acontecer às retomada dos estudos os Estudos Remotos Emergenciais. Segue a relação de temas tratados nas rodas de conversa realizadas:

- Repositórios Educacionais Digitais

- Google Meet

- Criando Tutoriais

- Ferramentas GSuite for Education 
- Google Classroom: como usar a sala virtual para professores e alunos

- Avaliações On-line utilizando o Formulários.

- Docência Compartilhada: Engajar e Motivar: atributos de jogos nas práticas educativas.

- Estudos Autônomos, Estudos Orientados e Aprendizagem Baseada em Projetos: fundamentos e metodologia de trabalho.

- Montando a sala virtual com Roteiro de Estudos Orientados.

- Estratégias de engajamento e protagonismo dos estudantes em ERE.

- Mapas conceituais.

- Plano de Ensino e Roteiro de Estudos Orientados (REO).

- Montando a sala virtual com Roteiro de Estudos Orientados utilizando o SIGAA da Pós-graduação.

- Gravando Podcast e vídeos no Loom.

- Transformando um Plano de Ensino da área de Engenharia em um REO.

- Uso de mapas conceituais como ferramenta de avaliação aprendizagem.

- Capacitação Aberta para Docentes: passo a passo para a construção de salas virtuais.

- Docência Compartilhada: Compartilhando experiências de virtualidade na oferta do Cálculo I.

- Semana do Passo a passo: Adicionando arquivos em sua sala no Campus Virtual.

- Semana do Passo a passo: Google Meet.

- Semana do Passo a passo: Fórum e Tarefa.

- Semana do Passo a passo: Glossário, Diário e Enquete.

- Semana do Passo a passo: Escolha de Grupo e Wiki.

- Semana do Passo a passo: Ensinado com projetos e gamificação.

- Estilos de aprendizagem do Passo a passo: Avaliação e acompanhamento de atividades.

- A subjetividade da relação docente-discente no contexto de estudos remotos.

- REO: tudo começa com o planejamento

- Apresentação e relato de experiência da disciplina da pós-graduação "Alavanca do Sucesso - Produtividade com Equilíbrio"

- RE0- Vamos falar sobre os desafios?

- Avaliação da Aprendizagem no Ensino Remoto Emergencial

- Passo a passo: Ferramenta Questionário como instrumento de avaliação (Parte 1 e2 )

- Passo a passo Ferramenta Formulário Google (Parte 1 e 2 )

- Docência Compartilhada: Práticas de avaliação da aprendizagem 


\section{Dialogia}

SILVA, Alexandre José de Carvalho; CRUZ, Sayonara Ribeiro Marcelino; SAHB, Warlley Ferreira. Entre o ideal e o possível: caminhos de formação docente por meio das rodas de conversa on-line

- Cursos abertos oferecidos:

- Curso passo a passo para montagem de sala virtual no contexto de estudos remotos emergenciais

- Curso Aprendizagem remota para discentes - MOOC

- Curso livre sobre Avaliação online utilizando o questionário do Moodle

Para acompanhar o alcance e efetividade das ações foram utilizados os relatórios de certificação do Sistema Integrado de Gestão (SIG) da Instituição. E para avaliar a efetividades das propostas disponibilizou-se uma enquete (recurso do Moodle) a cada roda de conversa e um questionário de avaliação usando o Google Forms. Esses instrumentos trouxeram dados que serão apresentados e discutidos a seguir.

\section{Avaliando o percurso}

Quanto ao alcance destas ações de formação docente, trazemos alguns dados quantitativos que demonstram sua capilaridade e também a adesão de boa parte dos docentes da Instituição. Observemos que também foi possível identificar a participação de estudantes de pós-graduação e dos servidores técnicos administrativos em ações do programa:

Imagem 1 - Números gerais da formação
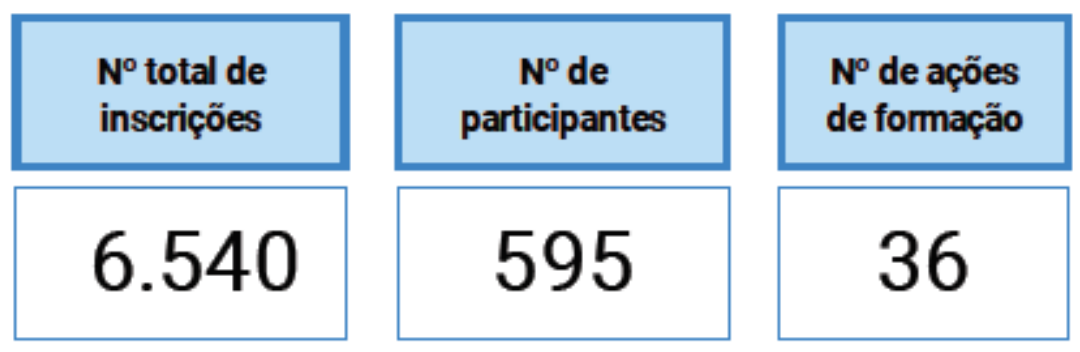

Fonte: SIG/UFLA e DADE/PROGRAD. (Disponível em

https://datastudio.google.com/reporting/1zs_a-y2C-xfvggmidkY38w8ei3PjuL-F. Acesso em: 03/07/2020). 
Imagem 2 - Distribuição de participação por categoria de inscrição

\begin{tabular}{|lc|}
\hline \multicolumn{2}{|c|}{ Participação - por categoria de inscrição } \\
\hline DOCENTE & 520 \\
\hline PÓS-GRADUAÇÃo & 40 \\
\hline N/I & 30 \\
\hline TAE & 5 \\
Total geral & 595 \\
\hline
\end{tabular}

Fonte: SIG/UFLA e DADE/PROGRAD. (Disponível em

https://datastudio.google.com/reporting/1zs_a-y2C-xfvggmidkY38w8ei3PjuL-F. Acesso em: 03/07/2020).

Podemos observar, nos dados trazidos pela Imagem 1 e Imagem 2, que quanto ao número de docentes participantes nas 36 ações de formação tivemos o correspondente a $2 / 3$ do número total professores da Instituição. Há também que destacar que as ações contaram com a participação de estudantes de pós-graduação, o que pode demonstrar a abertura das ações a esse público, atendendo a uma lacuna e necessidade proeminente de formação didático-pedagógica para atuação docente.

Para hospedar as gravações das rodas, as apresentações utilizadas e os materiais indicados foi criada uma sala virtual no Campus Virtual, o que possibilitou o acesso assíncrono aos docentes que não puderam participar das rodas de conversa e a oportunidade de revistar os materiais para tirar dúvidas e sistematizar os conhecimentos apreendidos. No período de realização das ações de formação tivemos o acesso de mais de quinhentos e sessenta (560) docentes à sala das rodas de conversa e 659 acessaram a sala destinada ao curso de passo a passo das ferramentas do Moodle.

Ainda em relação às evidências da capilaridade e alcance das ações de formação docente a que se refere este trabalho, podemos constatar, com base nos dados apresentados na Tabela 1, que a totalidade dos Departamentos que constituem a estrutura organizacional da UFLA tiveram representação nas ações de formação. 


\section{Dialogia}

SILVA, Alexandre José de Carvalho; CRUZ, Sayonara Ribeiro Marcelino; SAHB, Warlley Ferreira. Entre o ideal e o possível: caminhos de formação docente por meio das rodas de conversa on-line

Tabela 1 - Participação de docentes por Departamento

Departamento

$\mathbf{N}^{\circ}$ de Docentes participantes

\begin{tabular}{|c|c|c|}
\hline 1 & ADMINISTRAÇÃO E ECONOMIA & 35 \\
\hline 2 & AGRICULTURA & 19 \\
\hline 3 & AUTOMÁTICA & 8 \\
\hline 4 & BIOLOGIA & 27 \\
\hline 5 & CIÊNCIA DA COMPUTAÇÃO & 22 \\
\hline 6 & CIÊNCIA DO SOLO & 16 \\
\hline 7 & CIÊNCIA DOS ALIMENTOS & 25 \\
\hline 8 & CIÊNCIAS EXATAS & 27 \\
\hline 9 & CIÊNCIAS FLORESTAIS & 15 \\
\hline 10 & CIÊNCIAS HUMANAS & 10 \\
\hline 11 & CIÊNCIAS DA SAÚDE & 41 \\
\hline 12 & DIREITO & 11 \\
\hline 13 & EDUCAÇÃO & 16 \\
\hline 14 & EDUCAÇÃO FÍSICA & 7 \\
\hline 15 & ENGENHARIA & 50 \\
\hline 16 & ENGENHARIA AGRÍCOLA & 21 \\
\hline 17 & ENTOMOLOGIA & 8 \\
\hline 18 & ESTATÍSTICA & 8 \\
\hline 19 & ESTUDOS DA LINGUAGEM & 12 \\
\hline 20 & FITOPATOLOGIA & 2 \\
\hline 21 & FÍSICA & 17 \\
\hline 22 & GESTÃO AGROINDUSTRIAL & 6 \\
\hline 23 & MEDICINA VETERINÁRIA & 33 \\
\hline 24 & NUTRIÇÃO & 20 \\
\hline 25 & QUÍMICA & 25 \\
\hline 26 & RECURSOS HÍDRICOS E SANEAMENTO & 12 \\
\hline 27 & ZOOTECNIA & 19 \\
\hline 28 & NÚCLEO DE EDUCAÇÃO DA INFÂNCIA & 8 \\
\hline
\end{tabular}

Fonte: SIG/UFLA e DADE/PROGRAD.

Com o objetivo de realizar, paralelamente, uma avaliação do Programa PRODOCENTE por intermédio da realização das Rodas de Conversa On-line e também fazer um levantamento de 
demandas formativas para planejamento e oferta de outras formações, no início do mês de maio foi disponibilizado aos participantes um questionário, que obteve um total de 260 respostas.

Inicialmente devemos destacar o perfil dos participantes nas ações de formação. Conforme se observa, nos dados trazidos na Imagem 1, mais da metade dos respondentes informaram possuir mais de 10 anos de experiência docente, compreendendo assim - além da maior fatia do gráfico docentes que já devem ter passado por outros momentos de formação e mesmo assim marcaram presença nas formações das Rodas de Conversas On-line relatadas neste trabalho.

Gráfico 1 - Tempo de exercício na docência superior

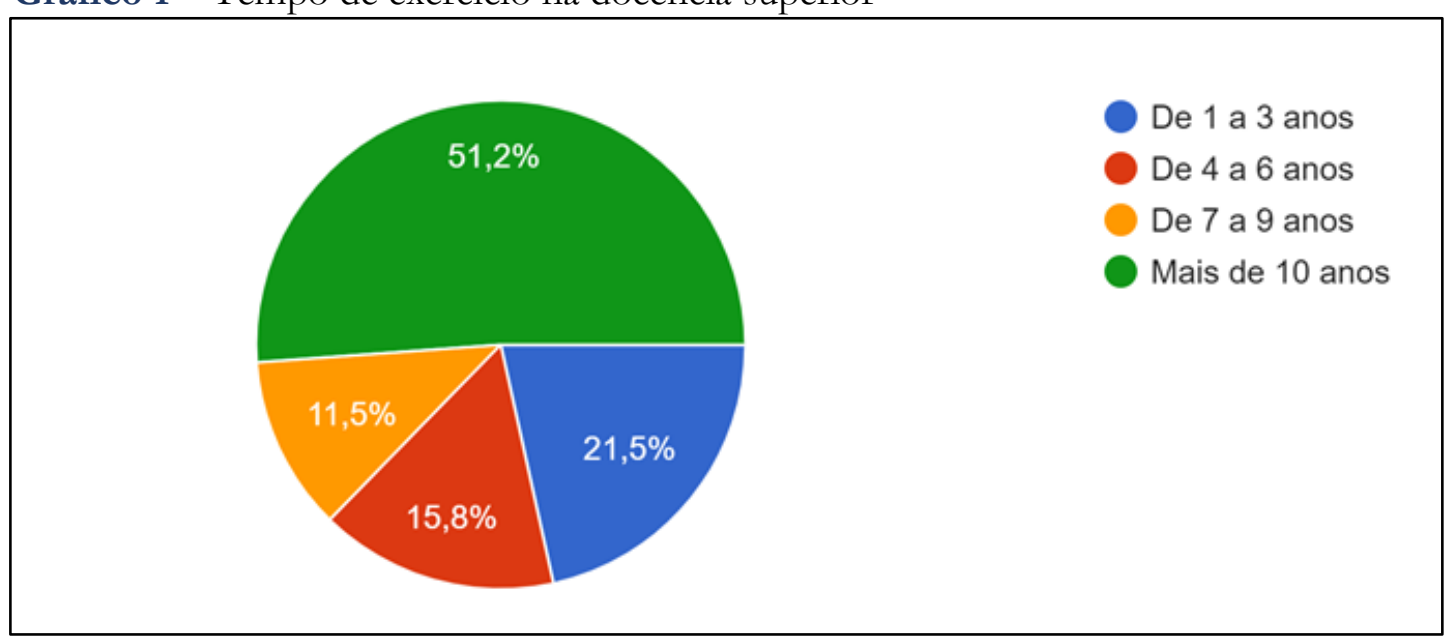

Fonte: DADE/PROGRAD.

Destaca-se ainda o número de docentes que informaram ter até 3 anos de experiência, que correspondem a 21,5\% dos respondentes. Em relação a estes respondentes vale destacar que as formações continuadas oferecidas pela DADE, em suas diversas ações, devem ser registradas e comprovadas por estes docentes no momento da realização de avaliações de estágio probatório, obrigatórias nos primeiros 3 anos de efetivo trabalho na Universidade.

Aproveitando a oportunidade de inquirir os docentes, inseriu-se no formulário uma questão cuja resposta pudesse proporcionar à DADE a opção de planejamento de ações de formações continuadas aos docentes no formato on-line, os resultados podem ser visto a seguir. 
Gráfico 2 - Tipos de ações

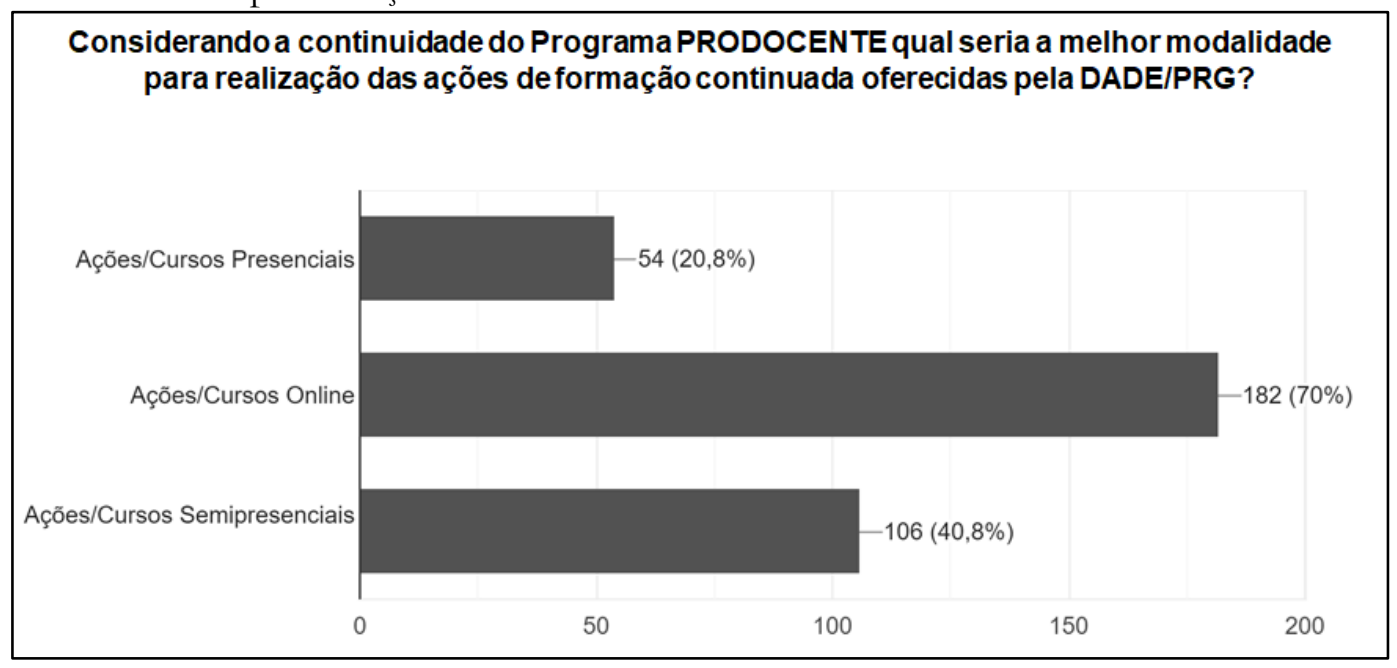

Fonte: DADE/PROGRAD.

Antes do início dos estudos remotos foi elaborado um questionário e solicitado aos docentes participantes das rodas de conversa que avaliassem este processo de formação; ao todo 106 pessoas responderam o questionário, o que representa cerca de $20 \%$ dos participantes.

Um dos principais objetivos das rodas de conversa era capacitar os docentes para o uso das ferramentas básicas do Campus Virtual da Instituição (Moodle) e para verificar a efetividade dessas formações foi perguntado qual a percepção dos docentes sobre seus conhecimentos tecnológicos antes das formações. As respostas mostram que, numa escala de 0 a 5, a maioria (69,8\%) respondeu que tinham conhecimento entre 2 e 3 , como pode ser visto no gráfico 3. Sendo importante destacar que $3,8 \%$ afirmaram que o conhecimento tecnológico era zero.

Gráfico 3 - Nível de conhecimento técnico

2) Qual o nivel de conhecimento técnico em relação ao Campus Virtual que você tinha antes da participação nas formações da Semana do Passo a Passo e das Rodas de Conversa On-line: 106 respostas

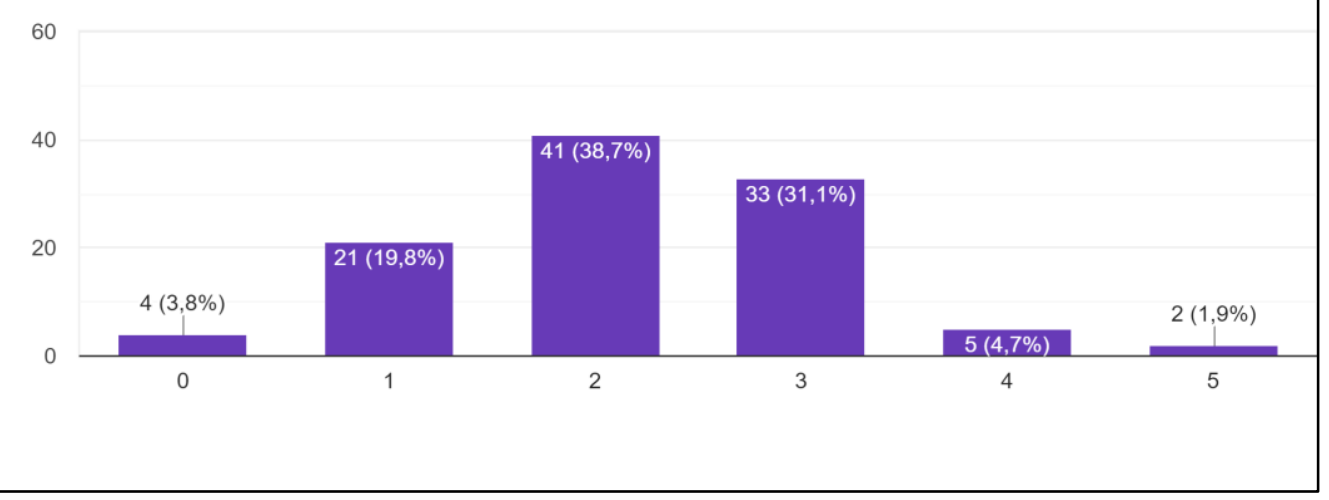

Fonte: DADE/PROGRAD. 


\section{Dialogia}

SILVA, Alexandre José de Carvalho; CRUZ, Sayonara Ribeiro Marcelino; SAHB, Warlley Ferreira. Entre o ideal e o possível: caminhos de formação docente por meio das rodas de conversa on-line

Após as formações, os docentes avaliados afirmaram que a percepção do conhecimento tecnológico havia subido bastante, sendo que nenhum dos avaliados mencionou conhecimento nível 0,1 ou 2 e a maioria $(68,9)$ respondeu que tem a percepção de nível 4 nos conhecimentos tecnológicos (TK).

Outro dado que comprova esta apropriação dos conhecimentos tecnológicos reside no fato de os docentes indicarem a intenção de utilizar uma variedade de recursos tecnológicos disponíveis, sendo que as ferramentas "tarefa e fórum" do Moodle e as transmissões de aulas via Google Meet foram apontados quais recursos foram mais utilizados na execução dos seus Roteiros de Estudos Orientados (REO), conforme Gráfico 4, valendo destacar que todos os recursos tiveram em maior ou menor número a manifestação de intenção de uso pelos docentes:

Gráfico 4 - Recursos mais utilizados

Quais dos recursos abaixo você pretende utilizar na execução dos seus Roteiros de Estudos Orientados (REO)?

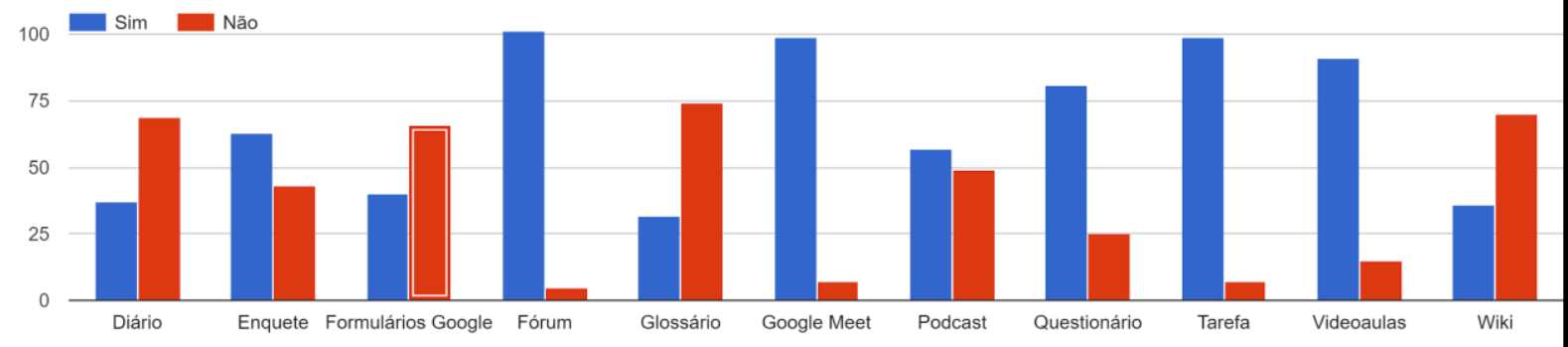

Fonte: DADE/PROGRAD.

A articulação dos conhecimentos tecnológicos ( PK) com os conhecimentos pedagógicos (PK) e conhecimentos de conteúdos( CK) foram avaliados nas questões 6 e 7 do questionário (gráficos 5 e 6), quando perguntamos sobre a escolha de estratégias de seleção de recursos tecnológicos/ferramentas mais adequados para um determinado conteúdo e abordagens metodológicas e pedagógicas que se encaixam em diferentes situações de aprendizagem: 
Gráfico 5 - Desenvolvimento de competências

6) Você considera que as formações lhe proporcionaram desenvolver competências para identificar estratégias de seleção de recursos te...o componente curricular sob sua responsabilidade? 106 respostas

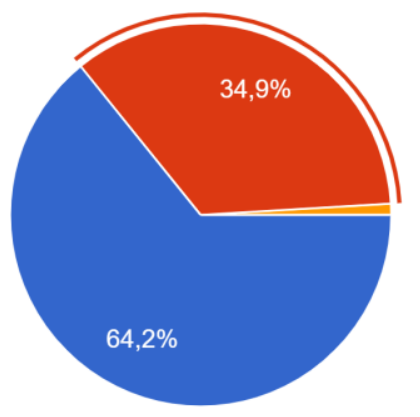

Sim, totalmente

Sim, parcialmente

Não

Não consigo avaliar

Fonte: DADE/PROGRAD.

Gráfico 6 - Abordagens Metodológicas e Pedagógicas

7) Você considera que as formações apresentaram discussões sobre abordagens metodológicas e pedagógicas que se encaixam em diferentes situações de aprendizagem:

106 respostas

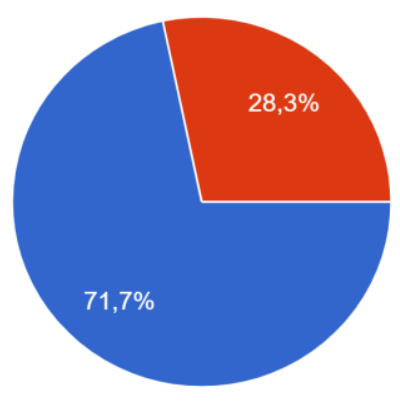

Sim, totalmente

Sim, parcialmente

Não

Não consigo avaliar

Fonte: DADE/PROGRAD.

Esses e outros dados recebidos por meio de e-mails e respostas abertas das enquetes evidenciaram a contribuição efetiva para boa parte dos docentes da instituição. Por outro lado, revelam a necessidade de criação de instrumentos que permitam avaliar a aquisição de competência digital dos docentes apontando por onde é preciso retomar ou ampliar as formações.

A aplicabilidade da estratégia de formação adotada e a pertinência das temáticas apresentadas foi logo comprovada com a adaptação e aplicação da proposta para a Secretaria Municipal de Educação de Lavras/MG. Assim, foi adaptado e elaborado um projeto de formação para o município no mês de julho, nos moldes do que foi realizado com os docentes da UFLA, certificando cerca de seiscentos e oitenta e seis (686) professores da rede municipal, colaborando 
diretamente para o planejamento do retorno das atividades escolares, até então totalmente suspensas no município. A articulação entre universidade e educação básica destacou-se como um caminho promissor para a difusão de conhecimentos produzidos e que, às vezes, levam muito tempo para chegar ao chão da escola.

\section{Considerações finais}

Fazer formações utilizando transmissões ao vivo ou curso on-line não é inédito na UFLA, porém, o ineditismo está no contexto vivenciado. Segundo Arruda (2020), o ineditismo leva a ações que precisam envolver toda a complexidade da qual faz parte. Esta complexidade se fundamentava no número grande de professores e estudantes que precisavam ser formados, na diversidade de temáticas que precisavam ser abordadas e nos conhecimentos pedagógicos e tecnológicos dos professores serem bastante heterogêneos.

Como a UFLA foi uma das primeiras universidades a definir a aplicação de ERE, não tivemos parâmetros de outras IES para organizar nossas ações, dando à iniciativa relatada esse caráter de ineditismo. As crises, como a pandemia, nos fazem pensar diferente e tentar coisas novas. Esta inovação está na capacidade de, em pouco tempo e num contexto de incertezas e imprevisibilidades, assumirmos o protagonismo das nossas ações e formarmos uma comunidade de aprendizagem colaborativa, reinventando a forma como fazemos a educação.

Paralelas à formação oferecida aos docentes, outras frentes de trabalho reuniram esforços e condições para que o calendário fosse retomado como, a elaboração de diretrizes, políticas de acessibilidade e flexibilização curricular. Destacamos a grande contribuição dessas ações articulados para a efetividade das ações de formação.

A receptividade da proposta foi grande entre os professores e, naturalmente, formou-se uma rede de colaboração e de troca de conhecimentos entre os envolvidos: professores de diferentes áreas compartilhando experiências de uso e refletindo sobre possibilidade de novas utilizações de recursos e metodologias. Toda esta interação foi extremamente rica.

Cerca de 30\% dos docentes não aderiram às propostas de formação no primeiro momento e um terço destes só vieram a participar quando foi confirmado os estudos de forma remota. Assim, especialmente para este público, foi elaborado o curso "Passo a passo para montagem de sala virtual no contexto de estudos remotos emergenciais" e muitos assuntos já abordados tiveram de ser novamente trabalhados. Os dois terços restantes que não participaram, segundo nossa inferência, podem ser classificados entre aqueles que já tinham os conhecimentos necessários e consideravam que não necessitavam das formações, e aqueles que iriam "terceirizar" o serviço de montagem das 
salas virtuais através da ajuda de estudantes orientandos e em estágio de docência e, por fim, o grupo dos que são ideologicamente contra os estudos remotos, a educação a distância e a educação mediada por tecnologias. A heterogeneidade em relação ao nível de apropriação e competência tecnológica pode ser usada a favor da formação de uma rede de aprendizagem colaborativa, uns aprendendo com os outros.

Em relação ao referencial que norteou o planejamento e a avaliação das ações, não se espera que seja um modelo teórico a ser usado de forma única ou capaz de apresentar técnicas prontas a ser aplicada em todos os contextos de formação docente. A TPCAK nos mostra muito mais desafios do que soluções. Desenvolver competências que pressupõem articulação entre conteúdos específicos, pedagógicos e tecnológicos, não é uma tarefa fácil ou simples, exige romper com o dualismo entre pedagogia e tecnologias, e superar paradigmas enraizados no sistema educacional. E o principal, reconhecer as TDIC como processos, para além de ferramentas, que precisam ser integradas aos currículos e concepções docentes, e aproveitar as lições aprendidas no contexto da pandemia para assim podermos avançar nas pesquisas, nas práticas e nos processos educacionais.

Face aos resultados obtidos, pode-se deduzir que propostas de formação continuada usando os espaços virtuais com atividades síncronas e assíncronas possibilitam adquirir competências para identificar abordagens metodológicas e pedagógicas que se encaixam em diferentes situações de aprendizagem utilizando as tecnologias. Nesse sentido, favorecem a inclusão digital no sentido despertar as competências docentes para a utilização das TDIC com autonomia e destreza, em consonância com as demandas da contemporaneidade.

O caminho percorrido apresentou-se eficaz no sentido de apoiar as ações dos professores que precisam adentrar no ensino mediado por tecnologias e poderá ser replicado e adaptado para diferentes contextos, inclusive no mundo pós-pandemia que, provavelmente, não dispensará as possibilidades inovadoras e as contribuições no sentido de promover uma educação mais dinâmica, interativa e inclusiva que as TDIC oferecem. Esta possibilidade foi reforçada nas avaliações realizadas com os participantes das formações, afirmando que no pós-pandemia este formato de realização das formações com rodas de conversas on-line deve permanecer, pois facilita a participação de mais pessoas de forma síncrona e também assíncrona, podendo alcançar muitas pessoas e sendo também específicas a determinados contextos.

O que se apreende da experiência de formação realizada no âmbito do ensino superior é que não se pode prescindir dos saberes e práticas vinculados ao uso e apropriação de tecnologias digitais para se manter a centralidade da escola como espaço de formação das novas gerações para o desenvolvimento socioeconômico e cultural. 


\section{Referências}

MISHRA, P.; KOEHLER, M. Technological Pedagogical Content Knowledge: A Framework, for Teacher Knowledge. Teachers College Record, v. 108, n. 6, p. 1017-1054, 2006.

COX, S., GRAHAM, C. R. Diagramming TPACK in practice: using and elaborated model of the TPACK framework to analyze and depict teacher knowledge. TechTrends, 53 (5), 60-69, 2009.

ALMEIDA, M. I. de. Formação do professor do Ensino Superior: desafios e politicas institucionais. São Paulo: Cortez, 2012.

CRUZ, S. R. M. Cruz; MARTINS R. X. Reflexões acerca da integração de tecnologias digitais na prática pedagógica de professores de História .Revista Educação e Linguagens, Vol. 5, nº 8, 2016.

CUNHA, M. I. da. Inovações pedagógicas: o desafio da reconfiguração de saberes na docência universitária. São Paulo: Cadernos Pedagogia Universitária - USP, 2008. Disponível em https://sites.unipampa.edu.br/formacao/files/2010/10/maria_isabel_da_cunha_caderno_vi.pdf. Acesso em: 27-07-2020.

SHULMAN, Lee S. Those Who Understand: Knowledge Growth in Teaching. Educational Researcher, v. 15, n. 2, p. 4-14, fev. 1986.

Recebido em: 16 nov. 2020/ Aprovado em: 01 dez. 2020

\section{Cite como}

\section{(ABNT NBR 6023:2018)}

SILVA, Alexandre José de Carvalho; CRUZ, Sayonara Ribeiro Marcelino; SAHB, Warlley Ferreira. Entre o ideal e o possível: caminhos de formação docente por meio das rodas de conversa on-line. Dialogia, São Paulo, n. 36, p. 348-366, set./dez. 2020. Disponível em: https://doi.org/10.5585/dialogia.n36.18701.

\section{American Psychological Association (APA)}

Silva, A. J. de C.; Cruz, S. R. M., \& Sahb, W. F. Entre o ideal e o possível: caminhos de formação docente por meio das rodas de conversa on-line. Dialogia, São Paulo, 36, p. 348-366.

https://doi.org/10.5585/dialogia.n36.18701. 